\title{
Pelvic pressure packing for intractable obstetric and gynaecological hemorrhage in a tertiary care hospital
}

\author{
Archana Bhosale, Kavya H. S.*, Yogeshwar Sadashiv Nandanwar, Ayesha Ansari
}

Department of Obstetrics and Gynecology, Lokmanya Tilak Municipal Medical College and General Hospital, Mumbai, Maharashtra, India

Received: 18 September 2018

Accepted: 22 October 2018

*Correspondence:

Dr. Kavya H.S.,

E-mail: drkavya89hs@gmail.com

Copyright: (c) the author(s), publisher and licensee Medip Academy. This is an open-access article distributed under the terms of the Creative Commons Attribution Non-Commercial License, which permits unrestricted non-commercial use, distribution, and reproduction in any medium, provided the original work is properly cited.

\section{ABSTRACT}

Background: Haemorrhage is one of the most common complication of any surgery. Haemorrhage can be arterial, venous or capillary ooze. Massive haemorrhage if not timely managed may lead to fatal consequences. There are various medical and surgical methods to control haemorrhage. This study aims to achieve hemostasis with the help of pelvic pressure pack in Obstetric and Gynaecologic surgeries when standard methods are failed and to evaluate efficacy of simple and modified technique of pack preparation.

Methods: This is an observational study of 11 cases conducted over a period of $4 \mathrm{yrs}$. This study reports modification of standard packing techniques which overcomes some of its limitations. Here the pack was used in different gynaecologic and Obstetric cases, where intractable haemorrhage was the major problem and standard methods to control haemorrhage had failed. Here a simple foley's catheter rolled with condom and filled with normal saline was used to prepare a pack and kept over the bleeding surface. This specific pack will adopt the shape of the body cavity it is inserted into, thereby causing pressure tamponade against bleeding surfaces. Pack was removed after 48-72 hours of insertion. Postoperative control of bleeding, patient stability and morbidity were studied.

Results: The pelvic pressure pack successfully controlled bleeding in $100 \%$ of cases without any morbidity and mortality.

Conclusions: In the contemporary management of post-hysterectomy or adhesiolysis induced uncontrolled pelvic bleeding and venous oozes, the pelvic pressure pack appears to be valuable and effective option, affording correction of coagulopathy and further stabilization. We believe all Obstetricians and Gynaecologists should be familiar with this simple safe and cheap potentially lifesaving technique.

Keywords: Condom tamponade, Foley catheter, Pelvic pressure pack

\section{INTRODUCTION}

Hysterectomy and caesarean sections are two of the most commonly performed procedures in the world. Haemorrhage is one of the most common complication of any surgery. Intraoperative haemorrhage is generally defined as blood loss exceeding $1000 \mathrm{~mL}$ or requiring a blood transfusion. ${ }^{1}$ Massive haemorrhage refers to acute blood loss of more than 25 percent of a patient's blood volume or bleeding that requires emergency intervention to save the patient's life. ${ }^{2}$ Therefore every surgeon should be proficient in performing various surgical methods to control intra operative haemorrhage like internal artery ligation, uterine artery embolization and haemostasis hysterectomy. But when the standard methods fail, or the patient goes into coagulation failure, pelvic pressure packing is the rescue measure.

Postsurgical Pelvic pack can be used to control hemorrhage from large raw surfaces, venous plexuses and other inaccessible areas as it can assume the shape of the cavity it is inserted into, thereby causing pressure 
tamponade. The purpose of this study is to make use of simple, modified and easy to prepare technique to achieve hemostasis by use of Pelvic pressure packing in Gynecological and Obstetric surgeries.

\section{METHODS}

A study was conducted over a period of 4 years from june 2014 to May 2018 in Lokmanya Tilak Municipal Medical College and General Hospital, a tertiary care hospital in Mumbai. The study involved observation of 11 cases of intractable hemorrhage in obstetrics and gynecological surgeries requiring pelvic packing in which standard methods to control hemorrhage had failed. Foleys catheter no 20, Condom, Warm normal saline

\section{Inclusion criteria}

- Cases with intractable haemorrhage

- Hemostatic sutures taken or poor access for suturing

- Failed medical management

- Internal iliac ligation done

- Disseminated intravascular coagulation.

\section{Exclusion criteria}

- $\quad$ Large arterial or venous bleed

- Good access to suturing

- Bleeding in the abdominal cavity.

With aseptic precautions, a condom is rolled over a Foley catheter (no. 20) and tied with a cotton thread on two sites $1 \mathrm{~cm}$ apart. This condom pack is brought into the abdominal cavity though a separate skin incision other than the primary skin incision. A $1 \mathrm{~cm}$ incision taken 2 finger breadth above anterior superior iliac spine at the spino-umbilical line. The condom is then inflated with warm normal saline until the pelvic bleeding is brought under control, that is usually up to around $1000 \mathrm{ml}$. Primary skin incision is then closed.

Patient has to be monitored closely in the ICU, transfusing blood and blood products, maintaining fluid and electrolyte balance and sending necessary investigations as and when required. Patient has to be kept on higher antibiotics to control infection. An indwelling urinary catheter avoids outflow obstruction by the pack and allows urine output to be monitored. The pack is then removed bedside without much difficulty by allowing it to drain by gravity after 48-72 hours.

These patients were closely monitored in ICU and then followed up till discharge from the hospital. The outcome parameters assessed with respect to success of treatment and complication occurred and measured as percentage.

\section{RESULTS}

There were 107 women enrolled in the study. Mean age of women was $27.1 \pm 4.05$ years. Of these $96(89.8 \%)$ women had preeclampsia, $11(10.2 \%)$ women had chronic hypertension with superimposed preeclampsia. Majority of women were either nullipara $(48.6 \%)$ or primipara $(33.6 \%)$. All the women were enrolled at 30 weeks onwards and umbilical artery and middle cerebral artery waveforms were recorded. Of 107 women, 79 (73.8\%) had mild disease and 28 (26.2\%) had severe disease at delivery. Abnormal umblical artery S/D ratio was seen in $31 / 110$ fetus $(28.2 \%)$. Umblical artery PI>2SD was seen in 33/110 fetus $(30 \%)$ and umblical artery RI> 2SD was seen in 38/110 fetus (34.5\%). Middle cerebral aretery RI < 2SD was seen in 46 fetus $(41.8 \%)$. The ratio of MCA and UA PI was abnormal in 42 fetus $(38 \%)$.

Table 1: Types of surgeries.

\begin{tabular}{|lll|}
\hline $\begin{array}{l}\text { Surgery } \\
\text { Cesarean } \\
\text { hysterectomy }\end{array}$ & $\begin{array}{l}\text { Ruptication uterus (3) } \\
\text { atonic PPH (2) }\end{array}$ & 5 \\
\hline $\begin{array}{l}\text { Wertheim's } \\
\text { hysterectomy }\end{array}$ & Carcinoma cervix & 2 \\
\hline $\begin{array}{l}\text { Total abdominal } \\
\text { hysterectomy }\end{array}$ & $\begin{array}{l}\text { Huge multiple uterine } \\
\text { fibroids surgery }\end{array}$ & 2 \\
\hline $\begin{array}{l}\text { Exploratory } \\
\text { laparotomy }\end{array}$ & $\begin{array}{l}\text { Endometriomas (1) } \\
\text { TO mass (1) }\end{array}$ & 2 \\
\hline
\end{tabular}

There was a total of 110 babies in the study including 3 sets of twins. There were $46(41.8 \%)$ babies with IUGR. Eleven major adverse outcomes were noted in the study2 stillbirths, 6 babies required immediate respiratory support and three babies had respiratory distress subsequently.

Of the 6 babies who required immediate resusucitation, one expired in immediate neonatal period due to birth asphyxia (intrapartum fetal distress at 32 weeks in woman with severe preeclampsia), one expired after 10 days due to metabolic complications and the rest four survived. Table 2 demonstrates the outcome parameters of the study. Control of haemorrhage and coagulation correction was achieved in almost all cases. There was no wound infection, mortality and neuropathy in the study group. Fever was seen in 2 cases which subsided within 48 hours with antibiotic coverage.

Table 2: Outcome parameters.

\begin{tabular}{|ll|}
\hline Parameter & Number/ percentage \\
\hline Control of haemorrhage & $100 \%$ \\
\hline Coagulation correction & $100 \%$ \\
\hline Wound infection & Nil \\
\hline Mortality & Nil \\
\hline $\begin{array}{l}\text { Abdominal compartment } \\
\text { syndrome }\end{array}$ & Nil \\
\hline Neuropathy & Nil \\
\hline Fever & 2 (subsided within 48 \\
\hline Sepsis & hours) \\
\hline
\end{tabular}




\section{DISCUSSION}

Pelvic haemorrhage has always been the concern of obstetricians and gynaecologists who are sometimes faced with situations where the usual surgical and medical measures are exceeded as well as the conservative surgery, thereby requiring alternative techniques such as:

\section{- Arterial embolization}

- Vascular ligation

- Pelvic packing

Pelvic haemorrhage during gynaecological surgery can be arterial or venous, and the latter is often the more difficult to control. Massive blood loss can lead to substantial morbidity such as disseminated intravascular coagulation, renal failure, adult respiratory distress syndrome, and can have fatal consequences. ${ }^{3}$ Therefore surgeon should be quick in decision making and reduce decision to action interval, thereby minimizing the morbidity and mortality. Bleeding vessels has to be identified and secured with sutures or diathermy. If this fails, pelvic packing is a well-established method to control persistent and lifethreatening venous bleeding when the source cannot be identified accurately, when haemorrhage continues despite internal artery ligation and coagulopathy develops. The pelvic packing allows temporary limiting of bleeding and loss of coagulation factors, which helps the resuscitator to restore blood volume and correct coagulation disorders. ${ }^{4}$ It is postulated that the inflated balloon exerts a pressure

that overcomes systemic arterial or venous pressure, leading to cessation of blood flow and formation of clot locally. ${ }^{5}$

The pelvic packing is a technique that has been used for decades and this in the context of persistent bleeding from several sources: liver injury, liver rupture, gynecological and rectal cancer surgery. ${ }^{6}$ There are many modalities of pelvic packing. ${ }^{4}$ We have described the use of a pelvic pack prepared using condom, foley catheter and normal saline, which is delivered transabdominally through a separate small $1 \mathrm{~cm}$ incision to successfully provide pelvic tamponade and arrest the haemorrhage. The pressure pack may be left in the pelvis for 48 to 72 hours. ${ }^{7}$ Condom is the best balloon as it can expand up to 20 litres and to stop bleeding one does not need to inflate it beyond one litre. Removal of the pack does not require re-laparotomy as it is inserted through a separate small incision by just allowing the normal saline to drain by gravity and withdrawing the catheter. The first case of this kind in British literature was published in the 1960s. ${ }^{8}$

The history of "pelvic pressure pack," dates back to 1926 as originally described by Logothetopulos, may be of tremendous benefit in controlling bleeding. This pack is also called the mushroom, parachute, or umbrella pack. The pack can be constructed of an x-ray cassette bag, filled with gauze rolls tied end to end, providing enough volume to fill the pelvis. The pack is introduced transabdominal y with the stalk exiting the vulva. Mild traction is applied by tying a liter intravenous fluid bag to the stalk and hanging it over the foot of the bed to gravity. An indwelling urinary catheter is needed to monitor urine output and to prevent urinary tract obstruction. Placement of percutaneous pelvic drains should be considered to monitor ongoing bleeding within the peritoneal cavity after the surgical procedure. ${ }^{9}$ In another study they used a sterile bowel bag and large moist pressure packs with their ends tied end to end. These packs and the bowel bag were then removed vaginally within 48 hours when the patient was haemodynamically stable and with a stable coagulation profile. $^{3}$

Administration of broad-spectrum antibiotics is suggested since there is a high incidence of febrile morbidity in these critically ill women. Other complications secondary to excessive pelvic compression such as peripheral neuropathy (shutter nerve, sciatic nerve), a lower vena cava syndrome and obstructive acute renal failure were described. ${ }^{10}$ Thus maintain optimal pressure becomes the prerequisite. However, the above described complications did not occur in present study as the condom pack can take the shape of the cavity it is inserted into, exerting adequate pressure to stop bleeding surfaces without causing undue pressure on other organ systems affecting its physiology.

The various benefits of pelvic packing are

- An atraumatic procedure

- Intervention done is easy, inexpensive and quick

- It conforms naturally to the contour of the pelvic cavity

- Condom catheter balloon exerts similar pressure to that of any other balloon

- Highly effective

- Limits blood transfusions

- Buys time for correction of DIC and referring patient to higher centers.

- Potentially life-saving technique \& reduces morbidity and mortality.

\section{CONCLUSION}

In the contemporary management of posthysterectomy or adhesiolysis induced uncontrolled pelvic bleeding and venous oozes, the condom balloon pelvic pressure pack appears to be valuable and effective option, affording correction of coagulopathy and further stabilization. Planning, preparing and practicing for a massive haemorrhage should be an integral part of resident training programme and we believe all Obstetricians and Gynaecologists should be familiar with this simple, safe, inexpensive and potentially lifesaving technique.

Funding: No funding sources 
Conflict of interest: None declared

Ethical approval: The study was approved by the Institutional Ethics Committee

\section{REFERENCES}

1. Harris WJ. Early complications of abdominal and vaginal hysterectomy. Obstet Gynecol Surv. 1995;50(11):795-805.

2. Santoso JT, Saunders BA, Grosshart K. Massive blood loss and transfusion in obstetrics and gynecology. Obstet Gynecol Surv. 2005;60(12):82740.

3. Wong L, Rao S, Barton DPJ. Transvaginal tamponade for intra-operative pelvic haemorrhage in gynaecological oncology patients. BJOG An Int J Obstet Gynaecol. 2003;110(7):707-9.

4. Cassels JW, Greenberg H, Otterson WN. Pelvic tamponade in puerperal hemorrhage. A case report. J Reprod Med. 1985;30(9):689-92.

5. S. Ferrazzani, A. Perrelli, C. Piscicelli S. De Carolis. Balloon Internal Uterine Tamponade: Experience with 39 Patients from a Single. 381-6
6. Dildy GA, Scott JR, Saffer CS, Belfort MA. An Effective Pressure Pack for Severe Pelvic Hemorrhage. Obstet Gynecol. 2006;108(5):1222-6.

7. YU SP, COHEN JG, PARKER WH. Management of Hemorrhage During Gynecologic Surgery. Clin Obstet Gynecol. 2015;58(4):718-31.

8. Parente JT, Dlugi H, Weingold AB. Pelvic hemostasis: a new technic and pack. Obstet Gynecol. 1962;19(2):218-21.

9. Dildy Iii GD. Postpartum hemorrhage: new management options. Clin Obstet Gynecol. 2002;45(2):330-44.

10. Finan MA, Fiorica JV, Hoffman MS, Barton DP, Gleeson N, Roberts WS, et al. Massive Pelvic Hemorrhage during Gynecologic Cancer Surgery: Pack and Go Back. Gynecol Oncol. 1996;62(3):3905.

Cite this article as: Bhosale A, Kavya HS, Nandanwar YS, Ansari A. Pelvic pressure packing for intractable obstetric and gynaecological hemorrhage in a tertiary care hospital. Int J Reprod Contracept Obstet Gynecol 2018;7:4956-9. 